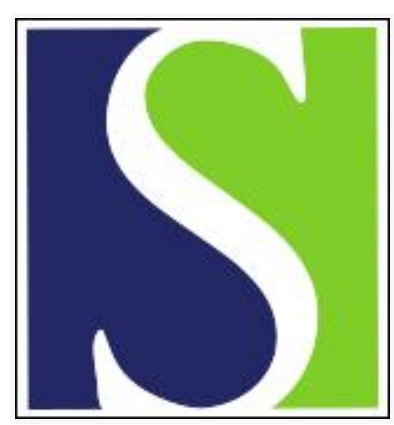

Scand J Work Environ Health 1984;10(6):505-509

https://doi.org/10.5271/sjweh.2293

Issue date: Dec 1984

\title{
Unemployment and mental disturbance.
}

by Lehtinen $\mathrm{V}$

This article in PubMed: www.ncbi.nlm.nih.gov/pubmed/6535253

\section{(c) (1)}




\title{
Unemployment and mental disturbance
}

\author{
by Ville Lehtinen, MD ${ }^{1}$
}

\begin{abstract}
LEHTINEN V. Unemployment and mental disturbance. Scand $J$ Work Environ Health 10 (1984) 505-509. Most of the investigations on unemployment and mental disorder tend to indicate that these two issues have a clear, but not very strong, association. The data from these studies seem further to indicate that this association is not a linear cause-effect relationship in either direction, but a circular or interactional relationship. Unemployment may affect mental health by acting as a precipitating factor. But, on the other hand, it is evident that the risk for the mentally disturbed to become unemployed is clearly greater than for other people. Many other factors besides unemployment and mental disorder act in this complex interaction network too. All unemployed are not similar, but such factors as age, education, domicile, family, other social ties, and personality have a great effect on the whole. Work is an important resource for mental health. Unemployment can be regarded as a risk factor because it means that the individual loses the positive and supporting elements which work has. The negative factors are (i) the lack of emotional and economic security, (ii) the perplexity of the time perspective, (iii) isolation, (iv) identity diffusion, and (v) a general sense of frustration.
\end{abstract}

Key terms: mental health.

In human life, work is of fundamental importance. It is essential for the survival of both society and the individual and makes it possible to satisfy certain basic human needs. It is through work that man has created both his material well-being and his abstract culture. Work confers security and the possibility of self-actualization. Man's innate propensity for activity and goal-directed behavior finds fulfillment specifically in work.

The industrial revolution, which began during the 18 th century, brought about radical changes in both the social structure and the nature of work. Work began to be concentrated in separate production units and finally came to form a totally separate area of human activity. It was only this development which made possible the occurrence of unemployment in the modern sense, a concept which gradually replaced the former ones of work-shyness, idleness, and immorality, used in connection with those who did not work. It is of course true that today, too, the unemployed are easily thus branded.

The present postindustrial stage of social development is characterized by a decline in the number of jobs in primary production and an increase in the number of jobs in the services and in planning and design occupations. In this computer age the individual is constantly flooded with information. Automation is gaining more and more ground in basic production and is taking over work formerly carried

\footnotetext{
1 Department of Psychiatry, University of Turku, Turku, Finland, and The Rehabilitation Research Centre of the Social Insurance Institution, Turku, Finland.
}

Reprint requests to: Prof V Lehtinen, Department of Psychiatry, Kurjenmäentie 4, SF-20700 Turku, Finland. out by human beings. The industrialized societies in particular will evidently need less and less human effort. This development inevitably means that work is becoming a kind of scarcity commodity, not available to everybody. Even today it seems evident that at least some degree of unemployment has become a permanent condition of society. In this situation, it is important to stop to consider the relationship between work or its absence on the one hand and mental health or disturbance on the other.

\section{Unemployment and mental health}

In purely theoretical terms, the relationship between unemployment and mental disturbance can take on a number of forms. At least the following alternatives are possible: (i) unemployment and mental disturbance are unrelated (indicated for example by a lack of statistical correlation between the two); (ii) unemployment and mental disturbance are correlated, but this statistical relationship is actually due to a third factor, which can be regarded as the cause of both [Between these two factors, on the other hand, there is no cause-effect relationship, according to which change in one factor (the cause) would inevitably be followed by change in the other (the effect).]; (iii) unemployment is a causative factor in mental disturbance; (iv) mental disturbance is a causative factor in unemployment; (v) there is a circular, mutually reinforcing causal relationship between unemployment and mental health.

Support for each of these alternatives can be found in the literature. Before going into the possible relationships between the two factors in greater detail, I 
shall briefly discuss the concept of mental health and consider the significance of work, and its absence, for the individual both generally and particularly, from the point of view of mental health.

\section{Mental health}

Mental health as a concept is neither straightforward nor unambiguous, and numerous definitions have been suggested. Without a clear understanding of what is meant by mental health, however, it is difficult to define mental illness or disturbance. In the following, I shall discuss in greater detail some ideas put forth by a research team of the Academy of Finland (11); these ideas are, in my view, particularly useful in this context, since they link the concept of mental health very closely to the social field. [See also the report of Lehtonen (7).] They therefore offer a good starting point for the consideration of the relationship between mental health and social phenomena (in this case unemployment).

Mental health can be defined as a human resource, similar to a renewable - evidently increasing natural resource. Mental health as a resource is one aspect of man's psychophysical being, with three basic dimensions, the biological, the psychological, and the social. Between the dimensions there is constant interplay, which regulates the development of mental-health forces in childhood, as well as the mental equilibrium of later life. The basis of mental health consists of a number of biological and psychological needs and abilities; when these are adequately met and actualized, the individual has an overall sense of mental balance and self-esteem, consisting of the feeling that one's life is meaningful and that one has both the ability and the opportunity to work and to gain gratification from the results of one's work.

The development of mental health is an ongoing process, the roots of which are present already at birth. This development is decisively affected by the individual's experience, particularly in childhood and adolescence; but the experiences and events of adulthood also play an important role. The response to the challenge of one stage of development crucially affects the next stage and its possibilities; this is one sign of the nature of mental health as an evolving, ongoing process. This process continues throughout the individual's life; at no time is mental health a static state but, on the contrary, a highly dynamic process. Mental health, in a very fundamental way, describes a relationship. It thus includes the individual's relationship with his psychological and physical self and its past history, with his social and physical environment - in particular his family - as well as the relationships within the community.

This concept of mental health as a human and social resource offers a good basis for a consideration of the relationship between mental health and unemployment. Through its actions society can enhance the development and growth of mental health, but it can also consume this resource to an extent exceeding its natural rate of renewal. In this way a social phenomenon becomes a factor leading to an increase in mental disturbance. The effect of unemployment on mental health may pass unnoticed until it becomes sufficiently extensive.

\section{Significance of work for the individual}

Work is significant to the individual in many different ways, which are related to the gratification of needs and which can also be seen as related to mental health as a human resource. According to Slocum (10), these functions can be divided into six categories: (i) work as a means of earning a living, (ii) work as a means of imposing a rhythm on time, (iii) work as a means of social interaction, (iv) work as a means of achieving a sense of identity, (v) work as a source of purpose and meaning in life, and (vi) work as a measure of social status.

The income that one earns from work is the most important source of livelihood. It is here the role of work as a source of security comes to the fore. In Maslow's (8) hierarchical classification of needs, the need for security comes second only to physiological needs. When these latter needs, the most compelling ones, are met, the most important regulator of one's behavior and inner world, and thereby also of mental health, is specifically a sense of security.

Regular work imposes an effective rhythm on use of time, dividing the day and the week into work time and leisure and the year into alternating periods of work and vacation. A regular rhythm of life gives the individual emotional support, wards off feelings of alienation, and provides a sense of meaningfulness.

Work provides a natural basis for integration into the larger social environment outside the family. The human need for social interaction is a basic one; the social relationships occurring at work are thus often very important. The quality of the individual's social relationships is another essential factor contributing to mental health.

In the relation to work and to fellow workers, man is able to test his own identity; these relationships provide, as it were, a mirror image of self-concept. One gains realistic information about one's own abilities, one's position in the community, and one's relationships in the immediate interpersonal milieu. A clear sense of identity leads to self-acceptance and realistic attitudes in relation to the environment in which one lives and toward other persons, factors which are again directly related to mental health.

Work helps to fill life meaningfully and gives a sense of satisfaction. It also offers an opportunity for self-actualization and the gratification of the need for purposeful activity. This state offers a good basis 
for personality growth and development and also for an increase in mental-health resources.

Finally, the individual's status in the community is to a great extent determined by his work and occupation. Work in itself provides a sense of being useful members of society. The possibility of career advancement also provides perspective into the future.

I have discussed the role of work primarily as a factor tending to support and increase the individual's psychic resources and mental health. It is possible, and in practice often the case, that these opportunities for need gratification are frustrated, in which case work becomes, on the contrary, a factor tending to consume mental-health resources and an actual risk factor for mental disturbance. These aspects will not be dealt with however; rather, I shall focus specifically on unemployment. Unemployment means that the aspects of work which I have mentioned - the sense of security, the rhythmic alternation of work and leisure, the opportunity for social interaction, the reinforcement of identity through such interaction, a meaning given to life, and social status - are absent.

\section{Empirical studies of the relationship between unemployment and mental health}

In particular in the United States a number of studies have been published showing a correlation between unemployment and the seeking of mental-health services. [See Brenner \& Mooney (3).] In the state of New York, for instance, a close relationship was found between the level of unemployment and the incidence of seeking psychiatric hospital care over a period of more than 50 years. Some studies have indicated an almost immediate time relationship between these factors, while others have suggested a "latency" period of up to five years before increased unemployment is reflected in the rate at which psychiatric services are utilized.

At the individual level, this relationship is generally very clear. A Finnish study by Salokangas (9), for instance, showed that the unemployment rate for patients who had sought psychiatric outpatient or inpatient treatment was almost fourfold in comparison to the rate for the society at large. Particularly among male psychiatric patients the occupational situation was poor.

An interesting finding was obtained in a study by Nieminen, not yet published, dealing with the correlations between factors related to the psychiatric services offered by the municipalities in a certain mental health district and other municipality-related data in 1973 and 1978. Nieminen's findings show that, in 1973, when the level of unemployment for the district as a whole was only $0.7 \%$, the correlation between the level of unemployment and the utilization of mental-health services was negative
$(-0.43)$, whereas, in 1978, with the level of unemployment up to $7.3 \%$, this correlation was found to be clearly positive $(0.44)$. This finding supports the view that the effect of unemployment on mental health is not evident, at the population level, until unemployment has reached a certain rate.

The risk of suicide or of suicide attempts has been associated with unemployment in a number of surveys. At least three recent American studies have been able to demonstrate a direct relationship between unemployment and suicide rates (3). On the other hand Kreitman \& Platt (5) reported, in their very recent review concerning the United Kingdom, that during the period 1962-1971 a rise in unemployment rates coincided with a decline in suicide rates. A closer analysis showed however that the decline in suicide rates was associated with the detoxification of domestic gas. When suicides by gas asphyxiation were excluded, the unemployment and suicide rates for the years 1955-1980 were found to have a close correlation.

In Finland, Yliranta \& Liikkanen (13) have carried out a study of unemployment and suicide in Lapland, an area with one of the highest unemployment rates in Finland. They concluded that unemployment could not be shown to be an important causative factor for suicide.

Epidemiologic studies have shown a positive, though not very strong, correlation between unemployment and the occurrence of mental disturbance. A Finnish study by Väisänen (12), for instance, which dealt with the population of working age of two separate districts, showed that individuals who had been unemployed frequently or for long periods also had various mental disorders more commonly than others (table 1).

As can be seen from table 1, almost one-half of those with frequent or long periods of unemployment were found to have a mental disorder in comparison to one-fourth of those who had not been unemployed. A follow-up study of these subjects (6) was carried out five years later. It appeared that $19.6 \%$ of the new psychiatric cases detected during the follow-up period had also been unemployed during the period, compared to only $6.2 \%$ of those who had not displayed mental disturbance during the same period. In other words this study showed a correlation between the incidence of mental disorders and unemployment.

Table 1. Association between occurrence of unemployment and mental disturbance (\%) according to Väisänen (12).

\begin{tabular}{lccr}
\hline \multirow{2}{*}{$\begin{array}{l}\text { Mentally } \\
\text { disturbed }\end{array}$} & Unemployed \\
\cline { 2 - 4 } & Never & Seldom & Often \\
\hline Yes & 25.3 & 28.3 & 48.4 \\
No & 74.7 & 71.7 & 51.6 \\
\hline Total & 100.0 & 100.0 & 100.0 \\
\hline
\end{tabular}


Table 2. Association between unemployment and prevalence (\%) of different individual characteristics in the Mini-Finland Health Survey.

\begin{tabular}{|c|c|c|c|c|c|}
\hline \multirow{3}{*}{$\begin{array}{l}\text { Variable for which prevalence } \\
\text { is considered }\end{array}$} & \multicolumn{4}{|c|}{ During the preceding year } & \multirow{3}{*}{$p$-Value } \\
\hline & \multicolumn{2}{|c|}{ Unemployed } & \multicolumn{2}{|c|}{ Employed } & \\
\hline & Unadjusted & Age-adjusted & Unadjusted & Age-adjusted & \\
\hline $\begin{array}{l}\text { Poor or rather poor self- } \\
\text { perceived health }\end{array}$ & 10.3 & 10.1 & 7.1 & 7.1 & 0.012 \\
\hline Dissatisfaction with friendships & 2.8 & 2.5 & 2.1 & 2.1 & 0.303 \\
\hline Dissatisfaction with marriage & 1.8 & 1.6 & 3.0 & 3.0 & 0.115 \\
\hline $\begin{array}{l}\text { Self-perceived mental } \\
\text { disturbance }\end{array}$ & 10.9 & 10.6 & 8.0 & 8.0 & 0.024 \\
\hline Excessive drinking of alcohol & 9.3 & 9.1 & 5.1 & 5.1 & 0.000 \\
\hline Tendency toward somatization & $27: 1$ & 26.4 & 21.3 & 21.4 & 0.003 \\
\hline $\begin{array}{l}\text { Caseness determined by the } \\
\text { General Health Questionnaire }\end{array}$ & 31.8 & 31.1 & 24.1 & 24.3 & 0.000 \\
\hline
\end{tabular}

Table 3. Association between unemployment and prevalence (\%) of mental disorders in the Mini-Finland Health Survey.

\begin{tabular}{|c|c|c|c|c|c|}
\hline \multirow{3}{*}{$\begin{array}{l}\text { Disorder for which prevalence } \\
\text { is considered }\end{array}$} & \multicolumn{4}{|c|}{ During the preceding year } & \multirow{3}{*}{$\mathrm{p}$-Value } \\
\hline & \multicolumn{2}{|c|}{ Unemployed } & \multicolumn{2}{|c|}{ Employed } & \\
\hline & Unądjusted & Age-adjusted & Unadjusted & Age-adjusted & \\
\hline Generally a psychiatric case & 17.2 & 16.8 & 13.4 & 13.4 & 0.021 \\
\hline Schizophrenia & 1.0 & 1.0 & 0.4 & 0.4 & 0.089 \\
\hline Other psychosis & 0.4 & 0.5 & 0.4 & 0.4 & 0.841 \\
\hline Neurotic depression & 5.1 & 5.0 & 3.7 & 3.7 & 0.113 \\
\hline Anxiety or phobic neurosis & 7.5 & 7.1 & 6.5 & 6.5 & 0.360 \\
\hline Other neurosis & 2.2 & 2.3 & 2.0 & 2.1 & 0.833 \\
\hline
\end{tabular}

Table 4. Logistic regression analysis on unemployment and certain background factors according to the Mini-Finland Health Survey.

\begin{tabular}{lcc}
\hline Variable & $\begin{array}{c}\text { Improvement in } \\
\text { the chi-square }\end{array}$ & p-Value \\
\hline Social class & 206.473 & 0.000 \\
Sex & 35.187 & 0.000 \\
Drinking of alcohol & 10.718 & 0.030 \\
\hline
\end{tabular}

a Correct classifications: $88.4 \%$.

Convincing results were obtained in a controlled prospective study by the English investigators Banks \& Jackson (2), who followed almost 3000 young persons two and a half years after the conclusion of school or studies. The investigation showed that, while women were at a higher risk of mental disorders than men, the association between unemployment and the presence of psychiatric symptoms was the closest of all, persisting after standardization for sex, ethnic background, and level of education. The study showed that the experience of unemployment tended rather to increase than to reduce the occurrence of mental symptoms.

\section{The Mini-Finland Health Survey}

Some preliminary findings are already available from the Mini-Finland Health Survey [see the report of
Aromaa (1)], which is being carried out by the Social Insurance Institution and the reports of which are now beginning to be published. These findings give a sharper picture of the association between unemployment and various aspects of mental health in Finland. The study has dealt with a sample of $8000 \mathrm{in}$ dividuals aged 30 or more years and drawn from a total of 40 areas situated in different parts of Finland. The sample was representative of the Finnish general population aged 30 years or more. The research method consisted of a personal health investigation of all subjects, including the use of questionnaires, interviews, and clinical examinations, and was designed to deal comprehensively with both somatic and psychic disorders. The cooperation rate was $90 \%$. The analysis dealt with in the present report concerned a subgroup consisting of all gainfully employed subjects in the age range 30 to 60 years, a total of 4238 individuals. Of these, $11.9 \%$ had been unemployed for at least some time during the preceding year. In the following discussion, I shall look at the prevalence rates of certain variables related to mental disorders, or to risk factors for such disorders, in the group with a history of unemployment on the one hand and in that without such a history on the other.

Table 2 shows the occurrence of self-perceived or reported factors in the two groups. There was a statistically highly significant association between un- 
employment and two factors, ie, excessive drinking of alcohol and a Goldberg's (4) General Health Questionnaire score above the break-off value. A tendency toward somatization was also statistically significantly more common among subjects who had been unemployed. A slight statistical association occurred furthermore between self-perceived poor general health and self-perceived mental disturbance. Variables such as satisfaction with one's friendships or marriage were, on the other hand, not statistically significantly related to unemployment.

Table 3 shows the association between the prevalence rate of clinically diagnosed mental disorders and the occurrence of unemployment. Mental disturbance was found more commonly for the unemployed group than for the others. On the other hand, there was no significant correlation between unemployment and the prevalence rate of any individual psychiatric disorder.

Finally, a logistic regression analysis was conducted with the following variables to explain the occurrence of unemployment: sex, age, social status, satisfaction with friendships, satisfaction with marriage, presence of mental disorder, drinking of alcohol, and tendency towards somatization. The results are shown in table 4.

Only three predictors emerged in the analysis, ie, social class, sex, and the drinking of alcohol. Of these, social class showed by far the closest association with unemployment. After standardization for social class and sex, only the drinking of alcohol, out of the variables relating to psychiatric problems, was able to add to the predictive power of the model; at its best, the model classified $88.4 \%$ of the cases correctly.

\section{Conclusions}

It is evident that the relationship between unemployment and mental disturbance cannot be dealt with as a linear cause-effect relationship; what is involved is a complex interplay between many other factors in addition to these two. Unemployment may play a role in mental disturbance by acting as a precipitating factor; on the other hand, it is evident that individuals suffering from a mental disorder are at a clearly higher risk of becoming unemployed than mentally healthy individuals. All unemployed, however, are not alike; factors such as age, education, place of domicile, family, other forms of social nexus, and, above all, personality factors play an important role.

The studies discussed in this presentation show that unemployment and mental disorders have a tendency to occur concurrently. According to epidemiologic studies, however, the association between these factors is not particularly strong. Considered at the level of aggregate variables, on the other hand, it seems that the correlation between unemployment and indicators of mental disturbance becomes stronger with a rise in the unemployment level.

Evidently further research is needed to aid the understanding of the complex interrelationships between unemployment and mental disturbance as a whole. In such research an attempt should be made to gain a more profound understanding of the way the experience of unemployment is linked with the personality development and structure of the individual concerned, in particular with his psychic defense mechanisms and self-esteem. On the other hand an extensive prospective study would be needed to demonstrate definitively the causal association between unemployment and the incidence of mental disorders if such an association indeed exists.

\section{References}

1. Aromaa A. The Social Insurance Institution's MiniFinland Health Survey: Aims, design and present stage. Social Insurance Institution, Helsinki 1981.

2. Banks $\mathbf{M H}$, Jackson PR. Unemployment and risk of minor psychiatric disorder in young people: Crosssectional and longitudinal evidence. Psychol Med 12 (1982) 789-798.

3. Brenner $\mathbf{M H}$, Mooney A. Unemployment and health in the context of economic change. Soc Sci Med 17 (1983) 1125-1138.

4. Goldberg DP. The detection of psychiatric illness by questionnaire. Oxford University Press, London 1972. (Maudsley Monograph 21).

5. Kreitman N, Platt S. Suicide, unemployment, and domestic gas detoxification in Britain. $\mathrm{J}$ Epidemiol Community Health 38 (1984) 1-6.

6. Lehtinen V, Väisänen E. Psykiatrinen sairastavuus ja hoidon tarve Suomessa. Vertaileva sosiaalipsykiatrinen seurantatutkimus. Social Insurance Institution, Turku 1979. (Kansaneläkelaitoksen julkaisuja AL 12).

7. Lehtonen J. Mental health as recurrent resource-like phenomenon and some considerations of suicide problems. Psychiat Fenn (1978) 139-142.

8. Maslow A. Motivation and personality. Harper \& Row, New York, NY 1954.

9. Salokangas RKR. Työttömyys ja psyykkinen terveys. Suom Lääkäril 35 (1980) 223-230.

10. Slocum WL. Occupational careers: A sociological perspective. Aldine, Chicago, IL 1966.

11. Suomen Akatemia. Mielenterveystutkimuksen tausta, nykytila ja tehtäväkenttä Suomessa. Helsinki 1976.

12. Väisänen E. Mielenterveyden häiriöt Suomessa. Social Insurance Institution, Helsinki 1975. (Kansaneläkelaitoksen julkaisuja AL 2).

13. Yliranta T, Liikkanen A. Työttömyys ja mielenterveyden häiriöt. Suom Lääkäril 37 (1982) 234-238. 